\title{
The competitiveness evaluation of the construction enterprise based on the strategy conformity
}

\author{
Miao Wang ${ }^{1, a}$, Wenjing $\mathrm{Li}^{1, \mathrm{~b}}$, Yingying Cai ${ }^{1, \mathrm{c}}$, Xiaoxi Guo ${ }^{1, \mathrm{~d}}$, Fan Yang ${ }^{1, \mathrm{e}}$, Mei \\ $\mathrm{Zhu}^{1, \mathrm{f}}$, and Xiaofei Hou ${ }^{1, \mathrm{~g}}$ \\ 1 State Grid Shandong Electric Power Research Institute , Jinan 250002, China; \\ asddkywm@163.com
}

Keywords: the competitiveness evaluation, strategic conformity, Interval-valued fuzzy soft set decision

\begin{abstract}
Along with the rapid social development, the competitiveness of enterprises is stronger and stronger. It is obvious that the enterprise long-term competitiveness depends on the preferable strategic development. Therefore, the scientific evaluation of enterprise strategic competitiveness is of great significance. Based on these, this paper evaluates the strategic competitiveness of the electric power construction enterprise from four dimensions, namely, the enterprise strategy, organization scale, the enterprise culture and enterprise resources, furthermore, we build the evaluation index system of construction enterprise, and use the interval fuzzy soft set to evaluate construction enterprise competitiveness. The analysis results of an actual case show that this evaluation method can objectively reflect the real situation of the electric power enterprise competitiveness and feasible in practical application. In the end, this paper provides reasonable suggestions in order to improve enterprise competitiveness.
\end{abstract}

\section{Introduction}

Enterprise competitiveness is the ability on keeping more effectively than other enterprises in a competitive market (consumers, including productive consumers) to provide products or services, and obtain the profitability and the comprehensive quality of development ${ }^{[1]}$.After joining the WTO in 2001, compared with many well-known foreign enterprises, Chinese construction enterprises need more and more competitive ${ }^{[2]}$. Generally, enterprises have incomplete industrial structure, the market operation ability becomes poorer and the technical management level is lower, which results in lacking of core competitiveness ${ }^{[3]}$. To consolidate the domestic market becomes an urgent need to enhance the competitiveness of enterprises. However, the first problem is to improve the effective and scientific of the competitiveness evaluation of the enterprise.

At present, the research on evaluating the enterprise competitiveness mainly is divided into two categories. One of them is the study of evaluation methods and models, including the method of linear weighted method, analytic hierarchy process (AHP), grey correlation decision and fuzzy comprehensive evaluation method and so on. Zhao Yanyun uses the standardization method to estimate the cultural industry competitiveness of 36 provinces (municipalities) in China ${ }^{[4]}$, and Zeng Yongmei builds the evaluation model to analysis the culture industry competitiveness using AHP, and uses this model to test the main competitiveness of cultural industry in province Hunan ${ }^{[5]}$. None of these above can accurately describe the indicator information and make the reasonable analysis on the index information. Thus, we cannot make the scientific evaluation of enterprise competitiveness.

According to the characteristics of the actual electric power construction enterprises, this paper builds the enterprise competitiveness evaluation system based on enterprise strategy conformity. Then, we make the analysis of enterprise competitiveness on the basis of the interval fuzzy soft set method. Therefore, we can make the enterprise competitive evaluation become more scientific and realize their own competitive advantage, disadvantage and growth potential, which can contribute to improve the long-term enterprises competitiveness and the potential for scientific and reasonable analyses. 


\section{The enterprise competitiveness Index system}

In enterprise strategy management, the scholar analyze the strategic management theory and strategic influence factors ${ }^{[6]}$, and conclude that the influence of the organizational structure of enterprise strategic competitiveness ${ }^{[7]}$. Therefore, the entrepreneurs think that the management ability of the enterprise strategic is the key factor of enterprise competitiveness ${ }^{[8]}$. To sum up, from four factors to estimate the enterprise competitiveness, namely the enterprise strategy ability, enterprise scale, enterprise culture and enterprise resource management research. Thus, this paper builds the index system from these four aspects, and analyzes the enterprise competitiveness based on the strategy conformity.

Management strategy is planning for stable development facing the changing environment for the enterprises, including strategic management ability and innovation ability ${ }^{[9]}$. In the process of enterprise strategy formulation and implementation, strategic management contains the strategic plans and becomes the reasonable specific performance standards, then, to complete them. With the market changes, the strategic adjustment is equally important to the enterprise survival and the long-term development ${ }^{[10]}$. In conclusion, the indicators contain the rate of target completion, innovation strategy and the strategic adjustment timely. Among them, the completion rate of target $=$ the number of target completion /the number of all the targets $* 100 \%$, this can directly reflect the degree and effect of enterprise strategy implementation and determine the strategic advantage of enterprises competitiveness. The strategic adjustment timely for the environment changes of strain capacity can reflect enterprise flexible competitive strategy. The ratio of Innovation strategy=the number of innovative strategy plans/the number of all the strategy plans*100\%, which can express the enterprise adaptability to the environment changes and reflect the long-term competitiveness of the enterprise.

Enterprise structure and scale is the dominant index in the process of enterprise competitiveness evaluation, which can directly reflect the existing competitiveness, and be changed in market environment for a long time under the condition of the enterprise competitiveness ${ }^{\text {[11] }}$. Enterprise structure and scale is divided into enterprise scale and the internal organization structure. Enterprise scale includes the production scale and ranking score, then, the production scale is to describe the average contribution to society of the enterprise, which reflects the enterprise's sustainable ability to society and the strength of the enterprise competitiveness; Enterprise ranking score can be identified through the enterprise scale, and reflects the enterprise brand factor for long-term competitiveness.

Internal organizational structure determines the enterprise resource configuration and the flow pattern, which has played a key role in the long-term competition ${ }^{[12]}$. The internal organization structure is divided into the completeness of the management system and the normalization of communication platform construction. The completeness of management system reflects the normal degree of enterprise internal management and is the key factor of the long-term development of the enterprise. The standardization of communication platform construction can express the degree of information sharing.

Enterprise culture determines the value orientation of the enterprise, the culture is the underlying determinant factor of enterprise development and not easy to be copied. The competitive advantage can maintain for a long time ${ }^{[13]}$. According to Charlie Liu, in the enterprise strategic transformation, the learning ability and social responsibility has significant influence on enterprise strategy positive correlation $^{[14]}$. Based on these, corporate culture is divided into culture shaping, learning ability, and social responsibility of management. As a source of competitive advantage, the enterprise culture shape is the key factor to ensure the long-term competitiveness. Culture shaping is divided into the identity of the enterprise values from employees and the rate of culture construction investment among all the investment. The identity of the enterprise values can reflect the cohesion of enterprise culture and is the potential long-term competitiveness. The rate of enterprise culture construction investment among all the investment = culture construction investment funds / overall construction funds $* 100 \%$, said the attention degree to the cultural construction, meanwhile can reflect the attention to the long-term competitiveness.

Enterprise group learning is an important means to enhance the competitiveness of enterprises, 
which not only can reflect the degree of training to employees, but also relate to enterprise's scientific and technological innovation achievement. Therefore, learning ability is divided into the rate of employee training coverage and the ratio of research expense. Among them, the rate of employees' training coverage $=$ the staff number of participating in training /the total employees * $100 \%$, illustrates the overall learning situation of the enterprise employees, can reflect the management learning effect of the staff. The rate of research funds =the research funds/the main earnings* $100 \%$, can reflect the ability of enterprise's innovation scientific research, is the key to support the enterprise long-term development.

To consider the long-term development of the enterprise, the enterprise should develop on the level of the society. Therefore, the contribution degree can reflect the enterprise long-term strategic development, at the same time, also can improve the popularity of enterprise, and can get the access to social recognition and trust, which is necessary for enterprise sustainable development in society. Based on this, the responsibility of the enterprise ability is divided into social contribution rate and the rate of contract completion. Among them, the rate of the social contribution $=$ the total of corporate social contribution/the average total assets * 100\%. The rate of the contract completion=the contract number/the number of all the enterprise contracts*100\%, which can reflect the enterprise credibility to the customers.

To analysis enterprise resource is the foundation of the enterprise management, the main basis of competitive advantage and the key point of the competition strategy. Enterprise resources include human resources, technology and equipment resources and economic resources. Thus, human resources can be divided into the ratio of professional and the education level of managers. Among them, the proportion of professional =the number of professions/tne number of all the staff* $100 \%$, can reflect the technical ability of the enterprise, under the market environment of high-speed development of science and technology, technical personnel's configuration can affect the long-term competitiveness; the education level of managers can reflect the competitiveness of the enterprise strategic management level.

For the electric power industry, the merits of the technology innovation and equipment resources will directly affect the effect of engineering construction, and then influence benefits of the whole project $^{[15]}$. Therefore, the technical equipment resource is the foundation of enterprise strategic development, equipment resources are divided into the technology adoption rate and the rate of power equipment. Among them, the adoption rate of innovation technology $=$ the output value of the top ten new technology/output value of the enterprise $* 100 \%$, refers to the level of technology innovation, and reflects the enterprise in the market environment, based on the creativity and adaptability of strategic adjustment; the ratio of power equipment=total power of self-owned machinery/ the number of all the staff* $100 \%$, which refers to the ability of the enterprise, the higher the rate of power equipment, shows that the enterprise has the stronger the ability to complete various types of major projects and has the stronger ability of the bidding competitiveness.

As the basic factors of production and operation of an enterprise, financial resources can directly affect the long-term strategic development of the enterprise, and the traditional performance evaluation is limited to the quantitative static evaluation of the financial aspects. From the point of view of enterprise strategy, we build financial index system and objectively reflect the long-term competitiveness of the enterprise. From the enterprise shareholder interests, financial resources can be divided into the rate of return on net assets and the rate of the main business revenue growth. The rate of return on net assets=net income/average shareholders' equity*100\%, reflects the rate of return on the enterprise owners' equity investment, namely the profitability of the enterprise; the rate of main business revenue growth= (main business income in current-main business income of the previous period)/main business income of the previous period $* 100 \%$, reflects the enterprise growth ability in the development process.

To sum up, we build the index system as shown in table 5 based on strategic degree of building enterprise competitiveness. 
Table 1 The variables of enterprise strategy competitiveness

\begin{tabular}{|c|c|c|}
\hline Attribute & Variable & Sub-variable \\
\hline Enterprise strategy & $\begin{array}{l}\text { The innovation and management of } \\
\text { enterprise strategy }\end{array}$ & $\begin{array}{l}\text { the rate of target completion } \\
\text { The ratio of Innovation strategy } \\
\text { The timeliness to adjust the enterprise strategy }\end{array}$ \\
\hline $\begin{array}{c}\text { Organization and scale of } \\
\text { enterprise }\end{array}$ & $\begin{array}{l}\text { The scale of enterprise } \\
\text { Internal organizational structure }\end{array}$ & $\begin{array}{l}\text { production scale } \\
\text { Enterprise ranking score } \\
\text { The standardization of the completeness } \\
\text { The normalization of communication platform } \\
\text { construction }\end{array}$ \\
\hline Enterprise culture & $\begin{array}{l}\text { Learning ability } \\
\text { Responsibility management }\end{array}$ & $\begin{array}{l}\text { the identity of the enterprise values from } \\
\text { employees } \\
\text { the rate of culture construction investment } \\
\text { among all the investment } \\
\text { the rate of employees' training coverage } \\
\text { The rate of research funds } \\
\text { The rate of social contribution } \\
\text { the rate of contract completion }\end{array}$ \\
\hline Enterprise resource & $\begin{array}{l}\text { Human resource } \\
\text { Technology resource } \\
\text { Financial resource }\end{array}$ & $\begin{array}{l}\text { the proportion of professional } \\
\text { the education level of managers } \\
\text { the technology adoption rate } \\
\text { the rate of power equipment } \\
\text { the rate of return on net assets } \\
\text { the rate of the main business revenue growth }\end{array}$ \\
\hline
\end{tabular}

\section{The multiple attribute decision-making model based on interval fuzzy soft set}

\subsection{Definition}

Definition 3.1.1: The initial theory of domain and parameter set are represented by $U$ and $E$, and $A \subseteq E, P(\mathrm{U})$ is the power set of $U$, and the soft set in the domain of discourse $U$ is $(F, A)$, and $F$ is the mapping of set which is composed by all the interval sets from $E$ to $U^{[16]}$.

Definition 3.1.2: The initial theory of domain and parameter set are represented by $U$ and $E$, and $(F, E)$ is called as the interval value fuzzy soft sets in the domain of discourse $U$, that is $F: E \rightarrow(P(U))$, and $I(P(U))$ is a set which is composed by the interval value fuzzy soft sets in the domain of discourse $U$.

Definition 3.1.3: The $(F, E)$ is called as the interval value fuzzy soft sets in the $U$, and $R_{A}=\left\{(u, e): e \in A, u \in F_{A}(e)\right\}$ is defined as the subset of $U \times E$, that can be called as the relationship of $(F, E)$.

$\chi_{R_{A}}$ is the characteristic function of $R_{A}$ :

$U \times E \rightarrow[0,1], \chi_{R_{A}}(u, e)=\left\{\begin{array}{l}F_{A}(e)(u),(u, e) \in R_{A} \\ 0,(u, e) \notin R_{A}\end{array}\right.$

If $U=\left\{u_{1}, u_{2}, \ldots, u_{m}\right\}, E=\left\{e_{1}, e_{2}, \ldots e_{n}\right\}$ and $A \subseteq E$, then $R_{A}$ can be expressed as follows:

\begin{tabular}{llcll}
\hline$R_{A}$ & $e_{1}$ & $e_{2}$ & $\ldots$ &.. \\
\hline$u_{1}$ & $\chi_{R_{A}}\left(u_{1}, e_{1}\right)$ & $\chi_{R_{A}}\left(u_{1}, e_{2}\right)$ & $\ldots$ & $\chi_{R_{A}}\left(u_{1}, e_{n}\right)$ \\
$u_{2}$ & $\chi_{R_{A}}\left(u_{2}, e_{1}\right)$ & $\chi_{R_{A}}\left(u_{2}, e_{2}\right)$ & $\ldots$ & $\chi_{R_{A}}\left(u_{2}, e_{n}\right)$ \\
$\ldots$ & $\ldots$ & $\ldots$ & $\ldots$ & $\ldots$ \\
$u_{m}$ & $\chi_{R_{A}}\left(u_{m}, e_{1}\right)$ & $\chi_{R_{A}}\left(u_{m}, e_{2}\right)$ & $\ldots$ & $\chi_{R_{A}}\left(u_{m}, e_{n}\right)$
\end{tabular}

The interval value fuzzy soft matrix is as follows when $a_{i j}=\chi_{R_{A}}\left(u_{i}, e_{j}\right)$, 


$$
\left[a_{i j}\right]_{m \times n}=\left[\begin{array}{cccc}
a_{11} & a_{12} & \cdots & a_{1 n} \\
a_{21} & a_{22} & \cdots & a_{2 n} \\
\vdots & \vdots & \cdots & \vdots \\
a_{m 1} & a_{m 2} & \cdots & a_{m n}
\end{array}\right]
$$

$G M_{m \times n}$ is all of the $m \times n$ interval value fuzzy soft matrix in the $U$.

Definition 3.1.4: If $a=\left[a^{L}, a^{U}\right], b=\left[b^{L}, b^{U}\right] \quad$ and $\quad l_{a}=a^{U}-a^{L}, l_{b}=b^{U}-b^{L}$, then $p(a \geq b)=\frac{\min \left\{l_{a}+l_{b}, \max \left(a^{U}-a^{L}, 0\right)\right\}}{l_{a}+l_{b}}$ is the possibility degree of $a \geq b$.

Definition 3.1.5: If $\left[a_{i j}\right]_{m \times n} \in G M_{n \times m},\left[a_{i j}\right]_{m \times n} \in G M_{n \times m}$, then compositional operation of the interval value fuzzy soft set is as follows:

$$
\left[a_{i j}\right]_{m \times n} \circ\left[a_{i j}^{\prime}\right]_{n \times m}=\left[c_{i j}\right]_{m \times m}=\sum_{k=1}^{n} a_{i k} * a_{k j}^{\prime}
$$

Where $G M_{m \times n} \times G M_{n \times m} \rightarrow G M_{m \times m}$, and $\quad a_{i k} * a_{k j}^{\prime}=\left\{\begin{array}{l}1, p\left(a_{i k} \geq a_{k j}^{\prime}\right) \succ \frac{1}{2} \\ 0, p\left(a_{i k} \geq a_{k j}^{\prime}\right) \leq \frac{1}{2}\end{array}, \quad\left[c_{i j}\right]_{m \times m}\right.$ is called as interval-valued fuzzy soft set comparison matrix.

\subsection{Calculation steps}

(1) The corresponding interval value fuzzy soft matrix $\left[a_{i j}\right]_{m \times n}$ is constructed by the interval value fuzzy soft set $(F, E)$;

(2) The transposed interval value fuzzy soft matrix $\left[a_{i j}\right]_{m \times n}$ is obtained;

( 3 ) The interval-valued fuzzy soft set comparison matrix $\left[c_{i j}\right]_{m \times n}=\left[a_{i j}\right]_{m \times n} *\left[a_{i j}^{\prime}\right]_{n \times m}$ is calculated;

(4) The optimal parameter $r_{i}$ and bad parameter $t_{i}$ of the object $x_{i}$ in the domain of discourse $U$ is calculated;

$$
r_{i}=\sum_{k=1}^{m} c_{i k}, t_{i}=\sum_{k=1}^{m} c_{k i}, i=1,2, \ldots, m
$$

(5) The score result $S_{i}$ of the object $x_{i}$ in the domain of discourse $U$ is calculated ${ }^{[17]}$.

\section{A case study}

The three medium-sized Electric power construction general contracting construction units of Beijing are selected to evaluate the competitiveness in the paper, and the three enterprises are represented by $A_{1}, A_{2}, A_{3}$.The forms of research mainly are questionnaire survey, supplemented by field interview, and combining the data which is collected through the network and news information is used to evaluate. Results 37 validated from 84 questionnaires are got. The network news data is collected from the yearbook and the company's web site, the data is processed from documents and network which is more reliable. The interval fuzzy soft set is applied to represent the indicators in the paper, which also ensures the authenticity and objectivity of each indicator data.

(1) First, the evaluation information is transformed into interval value, and the interval value fuzzy soft matrix is constructed 


$$
\begin{aligned}
& a_{1 j}=[[0.7,0.85],[0.55,0.68],[0.18,0.26],[0.56,0.70],[0.44,0.46],[0.78,0.86], \\
& {[0.67,0.75],[0.58,0.69],[0.66,0.75],[0.78,0.87],[0.66,0.75],[0.57,0.63],[0.08,0.13],} \\
& [0.27,0.29],[0.77,0.79],[0.76,0.83],[0.79,0.84],[0.36,0.44],[0.48,0.53]]^{T} \\
& a_{2 j}=[[0.7,0.85],[0.75,0.88],[0.58,0.63],[0.72,0.88],[0.72,0.74],[0.58,0.66], \\
& {[0.57,0.65],[0.88,0.93],[0.66,0.75],[0.78,0.87],[0.76,0.85],[0.77,0.83],[0.88,0.93],} \\
& [0.66,0.68],[0.79,0.81],[0.76,0.83],[0.67,0.74],[0.56,0.63],[0.58,0.67]]^{T} \\
& a_{3 j}=[[0.67,0.75],[0.66,0.78],[0.26,0.33],[0.72,0.88],[0.86,0.88],[0.37,0.46], \\
& {[0.26,0.35],[0.68,0.75],[0.66,0.75],[0.35,0.47],[0.76,0.85],[0.46,0.53],[0.38,0.42],} \\
& [0.17,0.19],[0.81,0.83],[0.58,0.64],[0.47,0.54],[0.37,0.45],[0.48,0.56]]^{T}
\end{aligned}
$$

(2) Second, $\left[a_{i j}\right]_{3 \times 9}{ }^{T}=\left[a_{i j}\right]_{19 \times 3}$ is obtained through transpose operation, and the interval-valued fuzzy soft set comparison matrix is calculated as follows,

$$
\left[c_{i j}\right]_{3 \times 19}=\left[a_{i j}\right] \circ\left[a_{i j}\right]^{T}=\left[\begin{array}{lll}
0 & 3 & 6 \\
3 & 0 & 5 \\
7 & 7 & 0
\end{array}\right]
$$

(3) Thirdly, $r_{1}=\sum_{k=1}^{m} c_{1 k}=9, \mathrm{r}_{2}=8, \mathrm{r}_{3}=14$ and $t_{1}=\sum_{k=1}^{m} c_{k 1}=10, t_{2}=10, t_{3}=11$ are obtained by the calculation.

(4) Finally, $s_{1}=r_{1}-t_{1}=-1, s_{2}=-2, s_{3}=3$ is calculated, and the sorting result is that the project $A$ is the optimal and the project $B$ is last. Therefore, the sorting result $r\left(A_{3}\right)>r\left(A_{1}\right)>r\left(A_{2}\right)$ is obtained.

It can be seen that the difference of sorting result is non-significant. However, the hard power of enterprise is almost the same in society. The enterprise competition ability can be decided by a little bit of gap, which cannot be ignored.

\section{Conclusion}

Based on the development of construction enterprises in our country, we build the index system of the enterprise strategy competitiveness, combining with the new requirements are put forward by the current increasingly fierce competitive environment, in order to reach the purpose of the enterprise strategic target, and use the evaluation model based on interval fuzzy soft set for comprehensive evaluation. To cater to the needs of business development of quantitative, it has much stronger practicability. The interval fuzzy soft set can effectively solve the uncertainty problem in the process of evaluation, and can make the established evaluation index has a strong stability and feasibility. All-round group decision-making also makes the evaluation results more credible. It is great that this model can enrich the decision method of electric power construction enterprise competitiveness, which has certain practical significance.

There are many influence factors of enterprise competitiveness, and the enterprise oriented strategy can obtain much bigger development space. Therefore, the innovation ability also can promote the transformation from cultural resources to the creative industries motivation. This conclusion can provide a basis for construction enterprises to improve market competitiveness, and provide reference for policy makers to make the scientific decision. Through horizontal comparative analysis between the companies, we can accurately identify the gap between the enterprises and the factors of this difference. At the same time, there are many deficiencies on selecting the index, because the data from recent years is not enough to completely reflect the comprehensive competitiveness of enterprises, furthermore, we need to deepen the research. 


\section{Reference}

[1] Onufriivna O O. The competitive strategies of the automobile construction enterprises: uropean experience and ukrainian realities [J]. Economic Processes Management, 2015: 3(1).

[2] Han G, Li Z. Notice of Retraction Study of HR management based on independent innovation in construction enterprises[C]// $\mathrm{E}$-Business and $\mathrm{E}$-Government (ICEE), 2011 International Conference on. IEEE, 2011:1-7.

[3] Jung J, Zhao Y. Alkali- or acid-induced changes in structure, moisture absorption ability and deacetylating reaction of $\beta$-chitin extracted from jumbo squid ( Dosidicus gigas ) pens[J]. Food Chemistry, 2014, 152:355-362.

[4] Ou Z, Xiong L, Li D Y, et al. Evaluation of a new fluorescence quantitative PCR test for diagnosing Helicobacter pylori infection in children.[J]. Bmc Gastroenterology, 2012, 13(1):1-6.

[5] Yang L, Li X, Fei S, et al. Responses of biomass briquetting and pelleting to water-involved pretreatments and subsequent enzymatic hydrolysis[J]. Bioresource Technology, 2014, 151C(1):54-62.

[6] Wang Z, Guo H, Fei S, et al. Biochar produced from oak sawdust by Lanthanum (La)-involved pyrolysis for adsorption of ammonium ( $\mathrm{NH} 4+$ ), nitrate (NO $3-$ ), and phosphate (PO $43-$ )[J]. Chemosphere, 2015, 119:646-653.

[7]Li-Hua R. Benchmarking China firm competitiveness: a strategic framework[J]. Journal of Technology Management in China, 2013, 2(2):105-118.

[8] Okolnishnikova I Y, Katochkov E V. RISK MANAGEMENT IN THE SYSTEM OF ENSURING THE COMPETITIVENESS AND STRATEGIC STABILITY OF ENTERPRISE STRUCTURES[J]. Modern Research of Social Problems, 2012(4).

[9] Cardinal L B, Alessandri T M, Turner S F. Knowledge codifiability, resources, and science-based innovation[J]. Journal of Knowledge Management, 2013, volume 5(2):195-204(10).

[10] Yang S L, Han R Z. Evaluation of science and technology innovation ability of provincial colleges and universities in China[C]// Management Science and Engineering (ICMSE), 2013 International Conference on. IEEE, 2013:2333-2340.

[11] Hwang J, Huang Y W, Vukovic M, et al. Enterprise-scale cloud migration orchestrator[C]// Integrated Network Management (IM), 2015 IFIP/IEEE International Symposium on. IEEE, 2015.

[12] Khilnani S, Swaminathan M, Chua C C. APPLICATION CONFIGURATION FRAMEWORK FOR ENTERPRISE RESOURCE PLANNING APPLICATION INSTALLATION: US, US 20130067456 A1[P]. 2013.

[13] Williams C C. Uncoupling enterprise culture from capitalism: Some lessons from Moscow[J]. Social Science Electronic Publishing, 2014, 8(2):111-125(15).

[14] Ivan G, Rafael G P, Aitor L A, et al. Bimatoprost 0.03\%/timolol 0.5\% preservative-free ophthalmic solution versus bimatoprost $0.03 \% /$ timolol $0.5 \%$ ophthalmic solution (Ganfort) for glaucoma or ocular hypertension: a 12-week randomised controlled trial.[J]. British Journal of Ophthalmology, 2014, 98(7):926-931.

[15] Katambara Z. Positioning Mbeya University of Science and Technology in Tanzania in the Systems of Innovation Perspective[J]. Advances in Applied Sociology, 2014, 04(01):20-23.

[16] Jiang Y, Tang Y, Liu H, et al. Entropy on intuitionistic fuzzy soft sets and on interval-valued fuzzy soft sets[J]. Information Sciences, 2013, 240(11):95-114.

[17] Alkhazaleh S, Salleh A R. Generalised Interval-Valued Fuzzy Soft Set[J]. Journal of Applied Mathematics, 2012, 2012(11):2607-2645. 